\title{
Picão-Preto: Uma Planta Daninha Especial em Solos Tropicais ${ }^{1}$
}

\author{
Black Jack: A Special Weed in Tropical Soils
}

SANTOS, J.B. ${ }^{2}$ e CURY, J.P. ${ }^{3}$

\begin{abstract}
RESUMO - Bidens pilosa está presente em praticamente todo o território brasileiro, além de vários outros habitats tropicais. Entre as caracteristicas presentes na planta, a abundante e longa produção de propágulos, o fotoblastismo preferencial, o uso eficiente da água, a elevada extração e utilização de nutrientes, bem como características morfofisiológicas específicas, conferem vantagem na competição com as principais culturas anuais e perenes. Devido à plasticidade e flexibilidade adaptativa de $B$. pilosa e às interações de suas características na determinação da competitividade desse vegetal, torna-se dificil identificar aquelas que realmente se associam com elevada capacidade competitiva e que possuam maior expressividade. Dentro da espécie ocorrem biótipos resistentes a determinados herbicidas, o que dificulta seu controle nas áreas agrícolas. O uso de outros métodos de manejo também possui entraves, devido à ampla variação do fluxo de disseminação, germinação e emergência de propágulos e, ainda, às associações benéficas dessa espécie com microrganismos presentes no solo. Embora seja dotada de características que a tornam infestante agressiva nas áreas agrícolas, este trabalho reporta alguns mecanismos que podem ser usados para o manejo integrado da espécie. Além disso, B. pilosa apresenta propriedades medicinais, sendo necessário o aprofundamento científico para usufruto de seus beneficios.
\end{abstract}

Palavras-chave: Asteraceae, Bidens pilosa, Manejo Integrado de Plantas Daninhas, polimorfismo germinativo, resistência a herbicidas

\begin{abstract}
Bidens pilosa occurs in practically all the Brazilian territory, besides several other tropical habitats. This plant's most advantageous aspects in the competition with major annual and perennial cultivars are its abundant and long propagule production, preferential photo-blastism, water use efficiency, high nutrient extraction and use, and morphophysiological characteristics. Due to B. pilosas plasticity and adaptative flexibility, as well as interaction of the characteristics determining its competitiveness, it is difficult to identify those which are associated with higher competitive capacity and expressiveness. This species presents biotypes resistant to some herbicides, rendering its control difficult in agricultural areas. The use of other management methods is also difficult, due to the wide variation in the flow of propagule dissemination, germination and emergence, as well as the beneficial association of this weed with microorganisms present in the soil. Although this plant has aggressive infesting characteristics, this work has reported some mechanisms that can be used for its integrated management. B. pilosa also presents medical properties, with extensive scientific studies being necessary in order to obtain benefits.
\end{abstract}

Keywords: Asteraceae, Bidens pilosa, Weed Integrated Management, germinative polymorphism, herbicide resistance.

\section{INTRODUÇÃO}

O gênero Bidens apresenta diversas espécies, entre as quais Bidens pilosa se destaca em todo o mundo, por ser uma planta daninha bastante agressiva e, ao mesmo tempo, espécie vegetal de elevado valor medicinal, em razão de suas propriedades farmacêuticas. Nos últimos anos, considerado número de trabalhos tem dado destaque a B. pilosa, por

1 Recebido para publicação em 6.11.2010 e aprovado em 10.3.2011.

2 Docente permanente do Programa de Pós-Graduação em Produção Vegetal, Universidade Federal dos Vales do Jequitinhonha e Mucuri - PPGPV/UFVJM, Campus JK, 39100-000 Diamantina-MG, <barbosa@ pq.cnpq.br>; ${ }^{3}$ Mestre em Produção Vegetal pelo PPGPV/UFVJM, <joaopcury@yahoo.com.br> 
suas propriedades fitotóxicas a outras plantas e a microrganismos. Nos campos agrícolas, ela apresenta ampla disseminação, devido às características de rusticidade tanto na produção de propágulos como no uso eficiente dos recursos, principalmente água e nutrientes, e condições edáficas e ambientais.

A denominação Bidens pilosa é originária do latim, em que "Bidens" significa dois dentes, referindo-se às duas projeções do aquênio, e "pilosa", devido à presença de pelos nas brácteas. A espécie tem como sinonímia: $B$. adhaerescens, B. alausensis, B. chilensis, B. hirsuta, B. leucantha, B. montaubani, B. reflexa, B. scandicina, B. sundaica, Coreopsis leucantha e Kerneria pilosa. Segundo classificação em Angiosperm Phylogeny Group III (APG III), pertence à ordem Asterales, família Asteraceae, tribo Coreopsideae, com ampla distribuição, encontrada nos trópicos e subtrópicos, desde o nível do mar até cerca de $3.000 \mathrm{~m}$ de altitude (Ballard, 1986). É citada como planta daninha em mais de 30 culturas, em pelo menos 40 países (Holm et al., 1991).

No Brasil, B. pilosa é encontrada em praticamente todo o território, porém concentrase nas áreas agrícolas da região Centro-Sul, onde se constitui numa das mais importantes plantas daninhas em culturas anuais e perenes, sendo sua presença quase constante em todas as épocas do ano.

Propõe-se, portanto, neste texto de revisão, abordar quais as características que tornam B. pilosa uma das mais competitivas espécies de plantas daninhas dos campos de produção agrícola e, ao mesmo tempo, planta medicinal de reconhecido valor, inclusive internacional. Paralelamente, tenta-se identificar características da espécie que poderiam ser usadas nas estratégias de controle, sobretudo visando ao manejo integrado.

\section{Morfologia}

Bidens pilosa é uma erva anual que atinge até $1,0 \mathrm{~m}$ de altura. As folhas são glabras, inteiras ou lobadas, sendo as superiores eventualmente internas, de 5 a $10 \mathrm{~cm}$ de comprimento.

As flores são dispostas em capitulos, individualmente acompanhadas por uma bráctea paleácea, que recobre o ovário (Júlio \& Oliveira,
2009). Os capítulos são poucos, pedunculados, reunidos em corimbos de 30 a 40 flores amareladas ou brancacentas, aromáticas; invólucro campanulado, escamas exteriores em geral foliáceas, quase sempre as interiores mais curtas, membranosas, brancacentas e ciliadas nas margens; poucas lígulas, brancas, frequentemente maiores que o invólucro, de dois a três lobos. Possuem brotos florais terminais compostos de flores tubulares radiadas de cor amarelo intenso (Valdés \& Rego, 2001).

Sua inflorescência é integralmente amarela e seus frutos, quando maduros, apresentam coloração enegrecida. Júlio \& Oliveira (2009) descrevem a ocorrência do pápus aristado, contido numa protuberância no ápice do pericarpo, formado por cerdas rígidas, em número de três a quatro, que apresentam tricomas voltados para a base. Essa estrutura se apresenta como cerdas rijas, que facilmente aderem ao pelo dos animais e tecidos, facilitando a disseminação (Duarte \& Estelina, 1999). Outros trabalhos descrevem o pápus como uma modificação do caule, utilizado na identificação dessa espécie devido à especificidade de suas características (Murherjee \& Sarkar, 2001).

O fruto é um aquênio linear-tetragonal, de 5 a $9 \mathrm{~mm}$ de comprimento, coloração marromescura e com extremidade superior provida de duas a três aristas. Segundo Júlio \& Oliveira (2009), a deposição de fitomelanina, que confere a cor negra ao fruto maduro, ocorre entre a região mais externa do mesocarpo e a região mediana deste. Conforme os autores, essa deposição tem início precocemente, quando comparada à de outras espécies do gênero. A fitomelanina é uma substância negra, caracteristicamente encontrada nos frutos de determinadas espécies da família Asteraceae e provavelmente relacionada à proteção do pericarpo.

Na base do fruto ocorre uma pequena projeção, o carpopódio, onde o fruto insere-se no eixo da inflorescência. A precocidade na maturação dos frutos está relacionada, além do acúmulo de fitomelanina, ao baixo número de camadas celulares. Essa característica, entre outras, comum à família Asteraceae, confere ao fruto pequeno crescimento em relação ao ovário que o produziu, tornando-o leve e facilitando o processo de dispersão. 


\section{Anatomia}

Quanto à caracterização anatômica, B. pilosa apresenta lâmina foliar com espessura aproximada de $200 \mu \mathrm{m}$, com epiderme simples e a face adaxial mais espessa que a abaxial. O mesofilo foliar é dorsiventral com pouca compactação; os parênquimas paliçádico e lacunoso apresentam quatro a seis camadas de células, com pouco mais de 100 e $70 \mu \mathrm{m}$ de espessura, respectivamente, mostrando-se em conformidade com o descrito para a maioria das Dicotyledoneae (Duarte \& Estelina, 1999). Tanto na face adaxial como na abaxial, os estômatos são classificados como anomocíticos. Entre as particularidades, pode ser destacada a maior presença de estômatos na face abaxial das folhas e tricomas tectores multicelulares não ramificados em ambas as faces das folhas. É provável que algumas das barreiras potenciais foliares à penetração de herbicidas constatadas em $B$. pilosa sejam a alta densidade tricomática, a baixa densidade estomática na face adaxial e o alto teor de cera epicuticular, principalmente na face adaxial. A taxa de vascularização foliar média dessa espécie é de, aproximadamente, um feixe a cada $200 \mu \mathrm{m}$ de largura foliar.

A bráctea apresenta secção transversal em $\mathrm{V}$ e epiderme com células de tamanhos variados, cuboides, de paredes finas e cutícula evidente, e alguns tricomas multicelulares em diferenciação; o mesofilo é composto por células parenquimáticas alongadas longitudinalmente, de tamanhos variados, entre as quais ocorrem vários feixes vasculares e canais secretores (Júlio \& Oliveira, 2009).

O caule em estrutura primária apresenta epiderme uniestratificada, cutícula estriada, tricomas tectores pluricelulares, unisseriados e alguns estômatos (Duarte \& Estelina, 1999). O limite interno da região cortical é determinado pela endoderme, apresentando estrias de Caspary evidentes e alguns amiloplastos (Valdés \& Rego, 2001). A endoderme típica é evidenciada no eixo caulinar, menos frequente em caule do que em raiz. Dutos secretores são encontrados nas proximidades dos feixes vasculares, nas regiões cortical e medular, com características semelhantes às dos dutos encontrados na raiz e nos demais órgãos vegetativos (Duarte \& Estelina, 1999).
A raiz constitui-se em estrutura primária com a epiderme uniestratificada e pelos radiculares, distinguindo-se claramente o sistema de revestimento, a região cortical e o sistema vascular (Duarte \& Estelina, 1999). Embora as Asteraceae apresentem pelos radiculares com paredes fortemente lignificadas, aqueles de $B$. pilosa são prolongamentos das células epidérmicas, raramente ramificados, com paredes delgadas, vacúolo conspícuo e núcleo evidente.

\section{Germinação e emergência}

Entre as principais espécies infestantes nas culturas anuais em solos tropicais, observa-se que a formação de sementes em Bidens pilosa é intensa, podendo chegar a 3.000 por planta; após a maturação, apesar de pequena proporção das sementes ter germinação imediata (Kissmann \& Groth, 1999), o número produzido pode comprometer a colheita.

A competição individual é tolerada pelas culturas, porém a espécie desenvolve-se em altas densidades nas áreas cultivadas, o que the confere grande capacidade competitiva. A profusa e longa produção de aquênios representa uma das principais características de agressividade da espécie - atributo este que garante sua sobrevivência em agroecossistemas.

A germinação desuniforme observada nas sementes de $B$. pilosa ocorre devido à dormência, que proporciona a sobrevivência e a viabilidade do banco de sementes em condições externas adversas. A confirmação da ocorrência de ciclos de dormência nas sementes apresenta fator fundamental na proposição de métodos mais racionais e eficientes de manejo de plantas daninhas. Práticas que estimulem a germinação de sementes no campo, como a aplicação de compostos superadores de dormência, apresentam chances muito maiores de sucesso se aliadas a condições ambientais favoráveis em termos de umidade, temperatura e pH do solo (Carmona \& Murdoch, 1995).

A germinação de sementes de $B$. pilosa não é dependente de luz (Klein \& Felippe, 1991), contudo, esse fato não se verifica em todas as situações. Amaral \& Takaki (1998), estudando 
a estrutura dos aquênios dessa espécie, verificaram que aqueles com tegumento verrugoso mostraram dormência e sensibilidade à luz, ao passo que os aquênios sem ornamento no tegumento não apresentaram dormência nem sensibilidade à luz, durante o processo de germinação. Testes comprovam que a viabilidade de sementes dessa espécie pode ser avaliada de forma satisfatória utilizando temperaturas alternadas de 20 e $30{ }^{\circ} \mathrm{C}$ com luz e nitrato de potássio (Carmona \& Villas Bôas, 2001), chegando a $35^{\circ} \mathrm{C}$ se enterradas a $1,0 \mathrm{~cm}$ de profundidade (Chivinge, 1996; Rios et al., 1989).

As sementes de $B$. pilosa germinam facilmente até $2,0 \mathrm{~cm}$ de profundidade, podendo permanecer dormentes por vários anos em profundidades superiores a $10 \mathrm{~cm}$ (Sahoo \& Jhá, 1998; Muniz Filho et al., 2004). Esses autores observaram elevada redução na germinação da espécie quando as sementes estavam em profundidades superiores a $2,0 \mathrm{~cm}$. Carmona \& Villas Bôas (2001) verificaram, para regiões de cerrado, que a germinação e o decréscimo de sementes de $B$. pilosa são mais rápidos na superfície do solo em relação às sementes enterradas a $10 \mathrm{~cm}$ de profundidade. Os autores também concluíram que a dormência secundária é induzida no período seco, reduzindo durante o período chuvoso, inferindo-se dessa forma a relação positiva da água sobre a infestação pela espécie.

Em áreas de solo propensas à inundação, Reddy \& Singh (1992) verificaram que a redução da germinação de $B$. pilosa pelo excesso de água é a principal causa da baixa infestação. Apesar disso, Adegas et al. (2003) relatam aumento do índice de velocidade de germinação para maiores períodos de embebição das sementes dessa espécie. No entanto, o baixo indice de velocidade de emergência, normalmente observado em plântulas de $B$. pilosa, pode constituir também parte da estratégia de sobrevivência dessa espécie para formação de densos bancos de sementes.

É provável que a infestação observada em ambientes mais intensamente modificados pelas práticas agrícolas, como os sistemas convencionais de plantio, seja decorrente da maior exposição dos frutos de $B$. pilosa à luz, em função do número de sementes enterradas que, mesmo antes dormentes, são expostas pelas ações de aração e gradagem. Em outra situação, sistemas com cultivos mínimos, como aqueles sob plantio direto, terão maior germinação e infestação dessa espécie, como resultado das sementes que ficaram sobre a superficie. Em ambos os casos, a água parece ser fundamental para o início da germinação. Assim, a duração dos períodos de embebição pode levar à germinação máxima de sementes (Chivinge, 1996) ou até reduzi-la (Reedy \& Singh, 1992).

A ocorrência de dormência quando as sementes de $B$. pilosa se encontram enterradas no solo constitui importante fator para a formação de densos bancos de sementes em solos submetidos ao preparo convencional, em razão da incorporação dos propágulos. Sob outro ponto de vista, se as hipóteses forem verdadeiras, a técnica do plantio direto deve acelerar o decréscimo de sementes de $B$. pilosa no solo, por concentrá-las próximo à superficie. Aparentemente, o preparo de solo e, como consequência, a variação nas condições edáficas alteram a dormência de sementes de $B$. pilosa.

A variação da capacidade germinativa de B. pilosa, nos experimentos conduzidos nas diferentes épocas do ano, é um ponto importante no manejo dessa planta. Esse comportamento pode ser intrínseco da semente e estar relacionado às condições fisiológicas da planta, por ocasião da frutificação, ou aos efeitos de solo e clima durante o processo de germinação e emergência das plântulas. Ainda, pode ser decorrente do efeito isolado ou da combinação de vários fatores fundamentais para o processo germinativo, como exposição à luz (Klein \& Felippe, 1991), necessidade de uma determinada amplitude de variação térmica e disponibilidade de água e oxigênio (Adegas et al., 2003), ou para o processo de emergência, como a quantidade de reservas para suportar o crescimento pela camada do solo.

\section{Competição por recursos de produção e eficiência de uso}

Bidens pilosa pode promover elevada extração de nutrientes; quanto maior a extração, maior será o potencial competitivo com a cultura de interesse. A espécie é capaz de acumular teores e quantidades totais relativamente altos de nitrogênio, fósforo e micronutrientes. $\mathrm{Na}$ avaliação realizada no final da formação de 
propágulos, em substrato com doses crescentes de fósforo, Procópio et al. (2005) observaram que plantas de feijão apresentaram menor conteúdo na matéria seca total de raizes, quando comparada a B. pilosa, para todos os niveis estudados do nutriente. Para estes autores, esse fato pode caracterizar desvantagem da cultura em competir por água e nutrientes, indicando também que o incremento no fornecimento de $\mathrm{P}$, caso não haja manejo adequado dessas espécies, pode favorecê-las em detrimento da cultura. Ainda conforme estes autores, B. pilosa foi a planta daninha que demonstrou maior eficiência na utilização de fósforo absorvido. Adicionalmente, o uso indiscriminado de fertilizantes pode promover o crescimento e desenvolvimento de plantas daninhas nas áreas agrícolas. Assim, a adequada aplicação dos nutrientes essenciais, além de ser correta do ponto de vista econômico e ambiental, é prática cultural necessária para a conservação do equilíbrio das infestações.

Pelo fato de o fósforo ser considerado nutriente de baixa mobilidade no solo, plantas de maior sistema radicular apresentam vantagem na captura desse elemento. Estudos nessa linha de pesquisa podem ajudar na resposta ao fato de a planta ter a tolerância em condições de elevada acidez dos solos e baixa disponibilidade de nutrientes, sobretudo fósforo.

Em relação à competição por água, é sabido que algumas espécies de plantas daninhas são mais competitivas quando o nível no solo é ótimo, e outras, quando ocorre déficit hídrico. No que se refere a $B$. pilosa, há pouca informação sobre o assunto. Entretanto, a espécie é uma das mais agressivas no uso da água e de outros recursos do solo nos principais cultivos agrícolas do Brasil.

A alta eficiência no uso da água é característica presente em plantas voltadas à sobrevivência e perpetuação, que resistem a ambientes limitados em recursos naturais, como a grande parte das plantas daninhas. O volume de solo explorado pelo sistema de raízes, a eficiência no uso da água e a capacidade de extração da água do solo determinam a capacidade competitiva de uma planta por esse recurso (Procópio et al., 2004). B. pilosa é amplamente conhecida por sua alta capacidade de extrair água do solo, embora não muito eficiente na utilização desse recurso quando comparada a espécies como Brachiaria plantaginea (Aspiazú et al., 2010). Sob condições de verão, com menor disponibilidade de água, $B$. pilosa tende a ser menos competitiva que B. plantaginea, devido à sua maior taxa de transpiração, baixa eficiência no uso da água e menor taxa fotossintética. No entanto, em condições extremas de déficit hídrico, $B$. pilosa pode tolerar mais a competição do que $B$. plantaginea, pois pode extrair água do solo mesmo em condições de baixo potencial hídrico (Aspiazú et al., 2010). Procópio et al. (2004) observaram que, quando o déficit hídrico foi induzido no estádio de pré-florescimento, as plantas de $B$. pilosa tiveram sua murcha permanente em solo mais úmido que as demais espécies, apenas não diferindo das plantas de soja, demonstrando a menor capacidade de extração de água do solo nesse estádio fenológico. Contudo, quando o déficit hídrico foi induzido após o início do enchimento de grãos, o teor de água no solo no ponto de murcha permanente (PMP) foi menor para as plantas de $B$. pilosa em relação às demais espécies avaliadas. Diante disso, esses autores sugerem que, nesse estádio, plantas de B. pilosa conseguem absorver água mais fortemente retida no solo, o que pode significar maior tolerância a veranicos em relação às demais, além da perpetuação em lavouras, devido à capacidade de completar seu ciclo e produzir propágulos, mesmo com reduzido fornecimento de água, fortalecendo o banco de suas sementes.

Em determinadas condições edafoclimáticas, a habilidade de uma planta em retirar a água presente no solo pode ser uma característica vantajosa para manutenção do seu desenvolvimento vegetativo. Entretanto, a recíproca também é verdadeira. Espécies de plantas que apresentam maior capacidade de utilização de recursos - entre eles, a água possuem maior potencial competitivo com culturas e espécies da comunidade infestante (plantas não cultivadas). Assim, a correta utilização de sistemas de irrigação e épocas alternadas de plantio das culturas agrícolas, entre elas o cultivo extemporâneo (denominado "safrinha"), podem promover o estabelecimento da cultura de interesse, aumentando 
sua capacidade de competição em detrimento das plantas daninhas.

Quando plantas estão submetidas à forte competição, as características fisiológicas do crescimento e desenvolvimento normalmente são alteradas, resultando em diferenças no aproveitamento dos recursos do ambiente, principalmente no uso da água, que influencia de modo direto a disponibilidade de $\mathrm{CO}_{2}$ no mesofilo foliar e a temperatura da folha e, consequentemente, a eficiência fotossintética da planta.

As sementes da maioria das espécies são protegidas, durante o seu desenvolvimento, por estruturas clorofiladas. As diferentes respostas à luz, no processo de germinação, seriam impostas por diferenças na capacidade de filttrar a luz solar, apresentadas pelos tecidos que protegem a semente em desenvolvimento. Ao amadurecer, a semente teria seu fitocromo aprisionado num estado fotoestacionário, determinado pela quantidade de luz recebida imediatamente antes de secar. Assim, sementes que amadurecem no interior de tecidos vegetais teriam a maior parte de seu fitocromo na forma inativa (Fv), necessitando do estímulo luminoso para a germinação. Nesse sentido, Klein \& Felippe (1991), avaliando os aspectos da germinação de propágulos de 43 espécies de plantas daninhas, verificaram que arquênios de $B$. pilosa apresentam fotoblastismo positivo, com germinação de $70 \%$. Entretanto, quando não foram estimulados pela luz, a porcentagem de germinação foi de $50 \%$, com temperatura constante.

O caráter "fotoblastismo positivo" nem sempre é absoluto, isto é, grande parte das espécies que, em laboratório, se comportaram como fotoblásticas positivas apresenta pelo menos alguma germinação no escuro. Em alguns outros casos, embora estatisticamente a espécie possa ser considerada fotoblástica positiva, esse caráter é apenas quantitativo, uma vez que tanto na presença quanto na ausência de luz ocorre considerável germinação de suas sementes. Esse comportamento (que poderia ser considerado como um fotoblastismo preferencial) foi observado em $B$. pilosa e em outras espécies de plantas daninhas, como: Xanthium strumarium e Euphorbia heterophylla. Adicionalmente, essa capacidade de variação tem consequências agroecológicas importantes, pois, no caso de $B$. pilosa, pelo menos algumas sementes germinarão, quaisquer que sejam as condições de luz do ambiente.

Várias espécies de plantas daninhas e culturas comerciais alteram a taxa fotossintética em diferentes níveis sob mesmas condições ambientais. Conforme Santos et al. (2003), B. pilosa apresenta elevado valor de razão de área foliar antes do florescimento, em relação às culturas da soja e do feijão. Esse fato pode sugerir uma adaptação da espécie na captação de luz nas fases iniciais do ciclo. Contudo, a planta daninha foi menos eficiente que a cultura quanto ao acúmulo de matéria seca e uso eficiente da radiação, demonstrando que, independentemente da maior capacidade de extração de recursos como água e nutrientes, nem sempre sua capacidade de conversão da radiação interceptada em massa vegetal será proporcional. Assim, o uso de cultivares com maior eficiência fotossintética, além de ser prática cultural pertencente ao manejo sustentável de plantas daninhas, pode promover aumento na capacidade competitiva da cultura.

A luz influencia indiretamente a abertura estomática, pelo seu efeito na assimilação de $\mathrm{CO}_{2}$. No entanto, a abertura estomática é menos dependente da concentração interna de $\mathrm{CO}_{2}\left(C_{\mathrm{i}}\right)$, respondendo à luz diretamente. Logo, em condição de competição e sombreamento, o balanço da luz participa no controle da abertura estomática e no balanço de gases entre a parte interna da folha e o meio externo (Loreto \& Bongi, 1989). Conforme Aspiazú (2010), a $C_{\mathrm{i}}$ da folha difere entre espécies: B. pilosa apresenta maiores níveis comparada a outras espécies, como Commelina benghalensis ou $B$. plantaginea, o que pode ser desvantagem, pelo aumento de $\mathrm{CO}_{2}$. A temperatura da folha também foi menor para $B$. pilosa em relação às duas espécies citadas. Esse fato pode ajudar a explicar a maior eficiência na fixação de $\mathrm{CO}_{2}$ para a espécie, mesmo apresentando o metabolismo tipo $\mathrm{C}_{3}$.

\section{Alelopatia}

Acredita-se que $B$. pilosa possua compostos naturais com efeitos alelopáticos sobre plantas, pragas e patógenos. Entre as substâncias 
presentes nessa espécie, a fenil-heptatrina (PHT) é um poliacetileno que, além de ser reconhecido como um complexo de importância ecológica e medicinal, constitui amplo espectro contra organismos concorrentes, possivelmente devido à produção de radicais livres tóxicos para eles, incluindo larvas de insetos herbívoros (Arnason et al., 1981), fungos (Arnason et al., 1980), bactérias (Khan et al., 2001), virus e outras plantas (Campbell et al., 1982).

Extratos aquosos de folhas secas de B. pilosa reduziram e/ou inibiram o percentual de germinação de sementes e o crescimento inicial de diversas espécies de plantas (Rabêlo et al., 2008), entre as quais Raphanus sativus (nabo-forrageiro) e cultivares de Lactuca sativa (alface) foram as mais sensiveis aos extratos. À medida que se aumentaram as concentrações destes, anormalidades no sistema radicular delas também foram verificadas, indicando efeito fitotóxico. Esses resultados confirmam as primeiras hipóteses de um composto natural ser considerado alelopático, pois, conforme Campbell et al. (1982), ele primeiramente deve ser tóxico para plantas concorrentes.

Há diversos métodos pelos quais as plantas podem liberar esses compostos no solo: por meio da decomposição da serapilheira, de processos mecânicos ou meios biológicos; compostos altamente voláteis podem ser vaporizados e exercer seus efeitos sobre outras plantas; as raízes podem liberar compostos por exsudação ou por decomposição mecânica ou biológica; e através da lixiviação de nutrientes das folhas pela chuva no solo. Para B. pilosa, a decomposição das folhas parece ter grande importância, pois o poliacetileno PHT é encontrado em altas concentrações no tecido foliar. Esse composto está presente em todos os órgãos de Bidens alba var. Radiata (Asteraceae), espécie estreitamente relacionada com B. pilosa; entretanto, as concentrações mais elevadas deste poliacetileno têm sido observadas nas folhas (Cantonwine \& Downum, 2001).

Diversas amostragens de $B$. alba na Flórida, EUA, demonstraram variações na concentração de PHT nas folhas dessa espécie ao longo do ano, sendo as maiores verificadas nos meses de julho a outubro (verão) (Cantonwine \& Downum, 2001).
As raízes liberam diversos ácidos orgânicos (oxálico, cítrico, málico, butírico, acético etc.), cuja concentração depende de fatores genéticos da planta e das condições de estresse às quais esta é submetida. Na rizosfera das plantas de $B$. pilosa foram identificados esses ácidos em quantidades superiores, quando comparada às demais espécies estudadas. Esses ácidos, além dos efeitos benéficos sobre a solubilização de nutrientes, podem preservar a região rizosférica do ataque de patógenos e/ ou atuar como agentes sinalizadores quando da simbiose com organismos promotores de crescimento e/ou desenvolvimento. Em contraste, se os nutrientes do solo são determinantes para as invasões de $B$. pilosa, a gestão deles, por meio de fontes, doses e épocas adequadas de fornecimento dos adubos, pode ser um meio eficaz para controlar a propagação dessa espécie invasora.

\section{Capacidade associativa à microbiota do solo}

Alguns estudos evidenciam que a disponibilidade da microbiota e de nutrientes do solo pode modificar a infestação por plantas daninhas. Contudo, é preciso reconhecer que há poucos trabalhos na literatura demonstrando os efeitos da atividade biológica e de organismos presentes no solo, associados ou não ao sistema radicular das plantas, sobre o crescimento e desenvolvimento destas. Cui \& $\mathrm{He}$ (2009) testaram as hipóteses de que a microbiota do solo associada a Dodoneae viscosa é mais benéfica para $B$. pilosa que para a espécie nativa Saussurea deltoidea e de que a espécie invasora é favorecida, em relação à espécie nativa, em solo rico em nutrientes, comparado com o solo mais pobre. Para testar ambas as hipóteses, esses autores conduziram um experimento em que $B$. pilosa e $S$. deltoidea foram cultivadas em solos estéreis e não estéreis, retirados próximos e distantes de arbustos de $D$. viscosa. Observou-se que a esterilização do solo teve maior efeito negativo no crescimento de $B$. pilosa que em $S$. deltoidea, indicando que os microrganismos associados a $D$. viscosa parecem ter efeito mais evidente na espécie invasora do que na planta nativa. Embora o solo retirado próximo a $D$. viscosa fosse significativamente mais rico em nutrientes do que o solo distante dessa espécie, essa diferença 
não promoveu efeito pronunciado na produção de matéria seca por $B$. pilosa, mesmo apresentando maior produção dessa variável no solo não estéril retirado próximo da espécie nativa.

Esses resultados sugerem que as invasões de $B$. pilosa sejam bem sucedidas por causa da presença da microbiota associada a outras plantas ao seu redor, mas não necessariamente aos nutrientes presentes no solo. Dessa forma, é provável que os microrganismos do solo possuam a capacidade de governar o processo de invasão de novas áreas por essa espécie invasora. Adicionalmente, esses resultados poderiam comprovar a dificuldade de controle de $B$. pilosa nas áreas quando for impossivel a remoção das demais espécies associadas aos grupos de microrganismos referidos. Nessas situações, a utilização de inimigos naturais pode ser um método de controle biológico para evitar a expansão de B. pilosa, associado ou não com métodos propostos por Browne et al. (2009), como boas práticas de manejo, prevenção da multiplicação e estudos da biologia da espécie. No entanto, esses métodos requerem mais testes para comprovação de sua eficácia em cada região e cultura estudadas.

\section{Resistência a herbicidas}

O método de controle mais utilizado para Bidens pilosa é o químico, com aplicação de herbicidas, uma vez que, se a eliminação for mecânica, pode-se esperar uma nova geração em poucos dias, visto que o revolvimento do solo traz à superficie sementes com condições de germinar (Ferreira et al., 2007). No entanto, dentro da espécie $B$. pilosa ocorrem biótipos, com graus de resistência a determinados herbicidas (Kissmann \& Groth, 1999).

Em várias pesquisas, a determinação da dose de herbicida necessária para controlar $50 \%$ da população $\left(\mathrm{C}_{50}\right)$ tem sido usada como forma de comprovação e determinação do nível de resistência de um biótipo de planta daninha. No caso do Brasil, o primeiro ensaio foi realizado por Christoffoleti et al. (1996). Foram conduzidos diversos experimentos em casa de vegetação, utilizando biótipos resistentes (R) e suscetiveis (S) de B. pilosa e doses crescentes de herbicidas inibidores da ALS. $\mathrm{O} \mathrm{C}_{50}$ foi determinado para os herbicidas imazethapyr, nicosulfuron, metsulfuronmethyl e chlorimuron-ethyl, o qual, com base nos resultados de matéria seca coletada 21 dias após a aplicação dos herbicidas, foi $370,39,26$ e 12 vezes maior para o biótipo resistente, comparado com o biótipo suscetivel, respectivamente (Christoffoleti, 2002).

Em outros trabalhos, Ponchio (1997), utilizando a técnica do bioensaios in vitro, comprovou ser a resistência de $B$. pilosa causada por uma alteração no sítio de ação. Assim, foi realizada a análise de regressão não linear para biótipos resistentes (R) e sensiveis (S), para vários herbicidas. A relação $\mathrm{R} / \mathrm{S}$, que corresponde à divisão do $\mathrm{C}_{50}$ do biótipo $\mathrm{R}$ pelo $\mathrm{C}_{50}$ do biótipo $\mathrm{S}$, foi estabelecida, comprovando assim a resistência do biótipo $\mathrm{R}$ de $B$. pilosa aos herbicidas chlorimuron-ethyl, imazethapyr, nicosulfuron e metsulfuron-methyl. Portanto, o biótipo $\mathrm{R}$ de $B$. pilosa apresenta resistência cruzada aos herbicidas inibidores da ALS. Entretanto, não existe diferença evidente nos padrões de crescimento entre os biótipos resistentes e suscetiveis de $B$. pilosa aos herbicidas inibidores da ALS sob ausência de competição, demonstrando que a modificação causada na ALS, que confere resistência, não se correlaciona com o decréscimo de produtividade pelas plantas. Ainda segundo esse autor, essa igualdade na produção indica que ambos os biótipos apresentam mesma adaptabilidade ecológica e ocupam nichos semelhantes no ambiente, sendo necessárias estratégias preventivas de resistência, pois, uma vez estabelecida uma população resistente, naturalmente ela não retorna para uma frequência original de suscetibilidade.

Em área cultivada com soja, após oito anos de manejo de plantas daninhas de folhas largas com herbicidas pertencentes aos grupos químicos das imidazolinonas (imazaquin e imazethapyr) e sulfonilureias (chlorimuronethyl), os índices de controle, nos últimos anos, principalmente de $B$. pilosa e $B$. subalternans, tinham sido abaixo dos insatisfatórios (Monquero \& Christoffoleti, 2001). Houve, nesse caso, a seleção de um biótipo resistente aos herbicidas inibidores da $\mathrm{AL}$, resultante da aplicação repetida desses herbicidas, que condicionou o aumento da frequência de alelos resistentes. 
A ocorrência de $B$. subalternans nas áreas agrícolas era pouco mencionada, provavelmente pelo fato de a espécie ser bastante semelhante a $B$. pilosa (Kissmann \& Groth, 1999). Essas podem ser consideradas uma única espécie, caso a taxonomia do grupo seja baseada exclusivamente em dados isoenzimáticos (Grombone-Guaratini et al., 2005).

A confirmação de que biótipos de $B$. subaternans são mais tolerantes do que B. pilosa a herbicidas inibidores da ALS revela a importância da identificação das espécies e das mutações pontuais nos genes resistentes a esse mecanismo de ação, o que pode possibilitar o esclarecimento dos padrões de resistência, fornecendo informações sobre sistemas alternativos de manejo, que podem prevenir ou retardar o aparecimento desta (LópezOvejero et al., 2006).

Herbicidas registrados para $B$. pilosa, não pertencentes ao grupo dos inibidores da ALS, quando aplicados isoladamente, controlam efetivamente a população resistente da espécie, o que indica a importância de rotacionar os mecanismos de ação em uma mesma área (Monquero \& Christoffoleti, 2001). Outra opção para os agricultores é a aplicação de herbicidas sobre a palha residual da cultura anterior.

\section{Uso medicinal e farmacologia}

Em todo o mundo, o gênero Bidens tem sido usado para tratar diferentes doenças, e no Brasil destaca-se a espécie B. pilosa (Oliveira \& Casari, 1999). Existem vários relatos populares que apontam para a utilidade de B. pilosa para contornar inúmeros desconfortos e enfermidades, incluindo inflamações, tumores e hepatite. Esses relatos chegam de Cuba, Bahamas, México, Equador, Peru, Panamá, Colômbia, EUA, região Sul do Brasil e Amazônia (Valdés \& Rego, 2001).

Os nativos da Amazônia empregam B. pilosa para doenças do figado e no tratamento da malária, sendo a atividade antimalárica devido à presença de poliacetilenos e flavonoides (Oliveira et al., 2004). Na Amazônia peruana, $B$. pilosa é utilizada no tratamento de afta bucal, angina, diabetes, desordens menstruais, disenteria, dismenorreia, conjuntivite, edemas, hepatites, icterícia, laringite, verminoses e febre aftosa em gado bovino. Essa espécie ainda é usada pelos povos indígenas para: dores de dente (principalmente a raiz), inflamação da garganta, retenção hídrica, lacerações, alívio de calafrios, blenorragia, leucorreia, tonsilites, infecções urinárias e vaginais (Valdés \& Rego, 2001). Adicionalmente, conforme esses povos, $B$. pilosa é utilizada também como emoliente, adstringente, antipirético, estimulante, desobstruente, diurético e sialogoga.

Praticamente todas as partes da planta são usadas nas preparações medicinais que são aplicadas por via tópica e/ou oral. As flores são empregadas para desconfortos gástricos em intoxicações alimentares e contra a diarreia, e decoctos das raízes são utilizados contra vermes e hepatite alcoólica. Entretanto, é na cutícula e nas células epidérmicas das folhas de $B$. pilosa que estão localizados os princípios ativos mais consumidos na área medicinal (Kviecinski et al., 2008) e na fitoterapia (Vasques et al., 1986).

Por se tratar de uma planta amplamente utilizada e conhecida, inúmeros estudos químicos já foram realizados, destacando-se aqueles sobre atividades antioxidantes. O chá adotado pela medicina popular é rico em quercetina (Hoffmann \& Hölzl, 1989; Valdés \& Rego, 2001) e outros compostos polifenólicos, que podem ser responsáveis pelas atividades antioxidantes observadas. A própria quercetina, em virtude de sua capacidade antioxidante in vivo in vitro, demonstrou anticarcinogenicidade em diversos estudos (Sundararajan et al., 2006; Kviencinski et al., 2008). Contudo, $B$. pilosa possui outras diversas substâncias já definidas quimicamente (Chiang et al., 2004), porém com efeitos ainda não relatados.

Nas últimas décadas, extensas investigações têm mostrado que essa espécie possui compostos com atividades anti-hiperglicêmicas (Ubillas et al., 2000; Hsu et al., 2009), antiúlceras (Tan et al., 2000), anti-inflamatórias (Khan et al., 2001), antitérmicas (Sundararajan et al., 2006), anticancerígenas e antitumorais (Sundararajan et al., 2006; Kviencinski et al., 2008), antioxidantes (Chiang et al., 2004), antivirais, antifúngicas (Deba et al., 2008) e antibacterianas (Khan et al., 2001). 
Extratos metanólicos das raízes de B. pilosa, nas concentrações de 5 a $10 \mathrm{mg} \mathrm{mL}^{-1}$, inibiram o crescimento de cepas de bactérias gram-positivas: Aereus aureus, Epidermidus aureus, Bacillus cereus, Micrococcus kristinae, Streptococcus faecalis; e gram-negativas: Escherichia coli, Pseudomonas aeruginosa, Flexneri Shigelia, Klebsella pneumoniae e Serratia marcescens (Ashafa \& Afolayan, 2009). Entretanto, de acordo com relatórios anteriores, extratos de folhas de $B$. pilosa foram ativos somente contra bactérias gram-positivas, mas não contra as cepas gram-negativas. É possivel que os extratos das raízes de $B$. pilosa possuam maior atividade antibacteriana, em relação aos extratos exclusivamente de folhas, pelo fato de a raiz ser um órgão de síntese de muitos compostos encontrados na parte aérea das plantas, e estes podem estar em maior quantidade nas raízes.

A inibição específica de bactérias entre as folhas e raízes dessa espécie pode, em parte, explicar por que a planta inteira é empregada no tratamento de infecções microbianas (Khan et al., 2001). Adicionalmente, compostos já relatados como eficazes no efeito alelopático a patógenos e/ou a outras espécies vegetais, como o poliacetileno PHT, flavonoides, alcaloides, esteroides, taninos, ácido linoleico e ácido linolênico, presentes em extratos de B. pilosa, possuem atividade antimicrobiana (Sundararajan et al., 2006).

\section{CONSIDERAÇÕES FINAIS}

Em comparação com outras plantas daninhas de folhas largas, Bidens pilosa é considerada de alto potencial competitivo (Rizzardi et al., 2003). Contudo, além de ser invasora bastante agressiva e de competir com as culturas por recursos de produção, pode servir de hospedeiro de pragas e doenças, podendo provocar perdas significativas de rendimento nos cultivos agrícolas (Kissmann \& Groth, 1999; Ferreira et al., 2007).

Bidens pilosa também é hospedeira de diversas espécies de fitonematoides pertencentes ao gênero Meloidogyne Goeldi, também conhecidos como nematoides de galhas. Apenas para Meloidogyne javanica, no Brasil foram relatadas 57 espécies de plantas infestantes que atuam como hospedeiras alternativas. Entre elas, B. pilosa destaca-se como uma das principais, pela ampla ocorrência nos ambientes agrícolas (Carmona \& Villas Bôas, 2001). Ainda pertencente ao gênero Meloidogyne, destaca-se o nematoide Meloidogyne mayaguensi, que parasita culturas de elevada importância econômica e diversas plantas daninhas - entre elas, B. pilosa (Carneiro et al., 2006). Outro ponto-chave é que $B$. pilosa é hospedeira de alguns fungos e de pragas como os afideos, também conhecidos como pulgões.

A literatura define B. pilosa como uma "planta daninha", por prejudicar direta ou indiretamente uma determinada atividade humana. A presença dessa espécie nos cultivos agrícolas pode interferir no processo produtivo, competindo pelos recursos de produção e condições do meio, liberando substâncias alelopáticas, atuando como hospedeira de pragas, doenças e nematoides e dificultando as práticas de colheita. Entretanto, ela vem se mostrando uma excelente ferramenta na área medicinal, com ampla variedade de compostos químicos, reconhecidos e utilizados em áreas como fitoterapia e farmacologia.

De maneira geral, as espécies invasoras, embora dotadas de rusticidade e agressividade competitiva, parecem ser extremamente sensíveis às condições ambientais. No caso de $B$. pilosa, as características que parecem mais contribuir para o caráter agressivo como daninha são: ciclo curto, com grande produção de sementes (aquênios); adaptação do propágulo reprodutivo com estruturas especializadas, permitindo maior leveza e aderência a animais e tecidos, além da grande deposição de fitomelanina, que protege o pericarpo, diminuindo injúrias e/ou predação; e alta densidade tricomática, baixa densidade estomática e alto teor de cera epicuticular, principalmente na face adaxial, como barreiras à entrada de herbicidas. Além disso, a planta apresenta elevado potencial no acúmulo de nutrientes como nitrogênio e fósforo e regulação da atração e/ou repulsão de microrganismos, provavelmente atribuído à característica de exsudação de uma variedade de compostos pelas raízes, tornando a rizosfera um ambiente altamente regulado e adaptado às variações ambientais. Essa mesma produção atípica de compostos confere as características medicinais peculiares da espécie. 
No que se refere à resistência de biótipos de B. pilosa a herbicidas inibidores da síntese de aminoácidos ramificados, é provável que a grande ocorrência de casos positivos seja atribuída ao intenso uso desse grupo de herbicidas, associado à elevada capacidade de dispersão das plantas não controladas.

Por outro lado, percebe-se na literatura como a antropização, principalmente por meio das atividades agricolas, promove a multiplicação da espécie em estudo. Os resultados de pesquisa enfatizam a agricultura convencional com aração e gradagem, seguida pela aplicação de herbicidas, como sendo o principal meio de propagação e manutenção do banco de sementes. É também evidenciado que práticas agronômicas que revolvem menos o solo, como o plantio direto, e ocorrências de campo, como a saturação (encharcamento) do solo, têm contribuído para diminuição da multiplicação dos propágulos reprodutivos de B. pilosa. Assim, simplesmente admitindo a adoção cada vez maior do sistema de semeadura direta, já se pode esperar diminuição da reinfestação por B. pilosa. Contudo, a significância na redução dos casos será diretamente proporcional ao investimento em outras práticas culturais, como a rotação de mecanismos de ação de herbicidas e de culturas, levando-se em consideração as fontes de adubo e a deposição precisa nas linhas de plantio.

Ademais, apesar da considerada literatura atribuída a $B$. pilosa, devem-se enfatizar as inúmeras hipóteses que ainda deverão ser testadas para a espécie. A riqueza de compostos químicos produzidos e a característica ímpar do sistema de raízes na captura de nutrientes e na relação com microrganismos merecem ser estudadas, visando elucidar mecanismos que podem ser empregados no melhoramento de plantas cultivadas e em fins biotecnológicos.

\section{AGRADECIMENTOS}

À Fundação de Amparo à Pesquisa do Estado de Minas Gerais - FAPEMIG e à Coordenação de Aperfeiçoamento de Pessoal de Nivel Superior - CAPES, pelo apoio às pesquisas na UFVJM.

\section{LITERATURA CITADA}

ADEGAS, F. S.; VOLL, E.; PRETE, C. E. C. Embebição e germinação de sementes de picão-preto (Bidens pilosa).

Planta Daninha, v. 21, n. 1, p. 21-25, 2003

AMARAL, A.; TAKAKI, M. Achene dimorphism in Bidens pilosa L. as determined by germination test. Braz. Arch.

Biol. Technol., v. 41, n. 1, p. 11-16, 1998

ARNASON, T. et al. Mosquito larvicidal activity of polyacetylenes from species in the Asteraceae. Biochem. Syst. Ecol., v. 9, n. 1, p. 63-68, 1981

ARNASON, T. et al. Photosensitization of Escherichia coli and Saccharomyces cervisiae by phenylheptatriyne from Bidens pilosa. Can. J. Microbiol., v. 26, n. 6, p. 698-705, 1980.

ASHAFA, A. O. T:; AFOLAYAN, A. J. Screening the root extracts from Biden pilosa L. var. radiata (Asteraceae) for antimicrobial potentials. J. Med. Plants Res., v. 3, n. 8, p. $568-572,2009$.

ASPIAZÚ, I. et al. Eficiéncia fotosintética y de uso del agua por malezas. Planta Daninha, v. 28, n. 1, p. 87-92, 2010.

BALLARD, R. Bidens pilosa complex (Asteraceae) in North and Central America. Am. J. Bot., v. 73, n. 10, p. 1452-1465, 1986.

BROWNE, M. et al. The crucial role of information exchange and research for effective responses to biological invasions.

Weed Res., v. 49, n. 1, p. 6-18, 2009.

CAMPBELL, G. et al. Allelopathic properties of alphaterthienyl and phenylheptatriyne, naturally occurring compounds from species of Asteraceae. J. Chem. Ecol., v. 8, n. 6, p. 961-972, 1982.

CANTONWINE, E. G; DOWNUM, K. R. Phenylheptatriyne variation in Bidens alba var. radiata leaves. J. Chem. Ecol., v. 27, n. 2, p. 313-326, 2001.

CARMONA, R.; MURDOCH, A. J. Interactions of temperature and dormancy-relieving compounds on the germination of weed seeds. Seed Sci. Res., v. 5, n. 4, p. $227-236,1995$.

CARMONA, R.; VILLAS BÔAS, H. D. C. Dinâmica de sementes de Bidens pilosa no solo. Pesq. Agropec. Bras., v. 36, n. 3 , p. $457-463,2001$.

CARNEIRO, R. M. D. G. et al. Identificação de Meloidogyne mayaguensis em goiabeira e em plantas invasoras, em solo argiloso, no Estado do Paraná. Nematol. Bras., v. 30, n. 3, p. 293-298, 2006. 
CHIANG, Y. M. et al. Metabolite profiling and chemopreventive bioactivity of plant extracts from Bidens pilosa. J. Ethnopharmacol., v. 95, n. 2-3, p. 409-419, 2004.

CHIVINGE, O. A. Studies on the germination and seedling emergence of Bidens pilosa and its response to fertilizer application. Trans. Zimb. Sci. Assoc., v. 70, n. 1, p. 1-5, 1996.

CHRISTOFFOLETI, P. J. et al. Imidazolinone resistant B. pilosa biotypes in the Brazilian soybean areas. In: MEETING OF THE WEED SCIENCE SOCIETY OF AMERICA, 36., 1996, Norfolk. Abstract... Champaign: WSSA, 1996. p. 10.

CHRISTOFFOLETI, P. J. Curvas de dose-resposta de biótipos resistente e suscetível de Bidens pilosa L. aos herbicidas inibidores da ALS. Sci. Agric., v. 59, n. 3, p. 513-519, 2002.

CUI, Q. G.; HE, W. M. Soil biota, but not soil nutrients, facilitate the invasion of Bidens pilosa relative to a native species Saussurea deltoidea. Weed Res., v 49, n. 2, p. 201-206, 2009.

DEBA, F. et al. Chemical composition and antioxidant, antibacterial and antifungal activities of the essential oils from Bidens pilosa Linn. var. radiata. Food Control, v. 19, n. 4, p. 346-352, 2008.

DUARTE, M. R.; ESTELITA, M. E. M. Anatomical characters of Bidens pilosa L., Asteraceae. Hoehnea, v. 26, n. 1, p. 15-27, 1999

FERREIRA, M. C. et al. Potenciação alelopática de extratos vegetais na germinação e no crescimento inicial de picãopreto e alface. Ci. Agrotec., v. 31, n. 4, p. 1054-1060, 2007.

GROMBONE-GUARATINI, M. T. et al. Low allozymic variation in the Bidens pilosa L. complex (Asteraceae). Biochem. Genet., v. 43, n. 7-8, p. 335-345, 2005.

HOFFMANN B.; HÖLZL J. Chalcone glucoside from Bidens pilosa. Phytochemistry, v. 28, n. 1, p. 247-249, 1989.

HOLM, G. L. et al. The world's worst weeds: distribution and biology. Malabar: Krieger, 1991. 609 p.

HSU, Y. J. et al. Anti-hyperglycemic effects and mechanism of Bidens pilosa water extract. J. Ethnopharmacol., v. 122, n. 2, p. 379-383, 2009.

JÚLIO, P. G. S.; OLIVEIRA, D. M. T. Morfoanatomia comparada e ontogênese do pericarpo de Bidens gardneri Baker e B. pilosa L. (Asteraceae). R. Bras. Bot., v. 32, n. 1, p. 109-116, 2009.
KHAN, M. R. et al. Anti-microbial activity of Bidens pilosa, Bischofia javanica, Elmerillia papuana and Sigesbekia orientalis. Fitoterapia, v. 72, n. 6, p. 662-665, 2001.

KISSMANN, K. G.; GROTH, D. Plantas infestantes e nocivas. 2.ed. São Paulo: BASF, 1999. Tomo II. 978 p.

KLEIN, A.; FELIPPE, G. M. Efeito da luz na germinação de sementes de ervas invasoras. Pesq. Agropec. Bras., v. 26, n. 7, p. 955-966, 1991.

KVIECINSKI, M. R. et al. Study of the antitumor potential of Bidens pilosa (Asteraceae) used in Brazilian folk medicine. J. Ethnopharmacol., v. 117, n. 1, p. 69-75, 2008.

LÓPEZ-OVEJERO, R. F. et al. Resistance and differential susceptibility of Bidens pilosa and B. subalternans biotypes to ALS inhibiting herbicides. Sci. Agric., v. 63, n. 2, p. 139$145,2006$.

LORETO, F.; BONGI, G. Combined low temperature-high light effects on gas exchange properties of jojoba leaves. Plant Physiol., v. 91, n. 4, p. 1580-1585, 1989.

MONQUERO, P. A.; CHRISTOFFOLETI, P. J. Manejo de populações de plantas daninhas resistentes aos herbicidas inibidores da acetolactato sintase. Planta Daninha, v. 19, n. 1, p. 67-74, 2001

MUNIZ FILHO, A. et al. Capacidade de emergência de picãopreto em diferentes profundidades de semeadura. R. Biol. Ci. Terra, v. 4, n. 1, p. 1-6, 2004.

MURHERJEE, S. K.; SARKAR, A. K. Morphological diversity of pappus in the subfamily Asteroideae (Asteraceae). J. Econ. Taxon. Bot. Add. Series, v. 19, ??n. ??, p. 275-295, 2001.

OLIVEIRA, F. Q. et al. New evidences of antimalarial activity of Bidens pilosa roots extract correlated with polyacetylene and flavonoids. J. Ethnopharmacol., v. 93, n. 1, p. 39-42, 2004.

OLIVEIRA, J. E. Z.; CASARI, V. W. D. Caracterização isozimática de acessos de Bidens pilosa L. R. Bras. Plantas. Med., v. 2, n. 1, p. 19-26, 1999.

PONCHIO, J. A. R. Resistência de Bidens pilosa L. aos herbicidas inibidores da enzima acetolactato sintase. 1997. 139 f. Tese (Doutorado em Agronomia) - Escola Superior de Agricultura "Luiz de Queiroz", Universidade de São Paulo, Piracicaba, 1997.

PROCÓPIO, S. O. et al. Ponto de murcha permanente de soja, feijão e plantas daninhas. Planta Daninha, v. 22, n. 1, p. $35-41,2004$. 
PROCÓPIO, S. O. et al. Absorção e utilização do fósforo pelas culturas da soja e do feijão e por plantas daninhas. R. Bras. Ci. Solo, v. 29, n. 6, p. 911-921, 2005.

RABÊLO, G. O. et al. Potencial alelopático de Bidens pilosa L. na germinação e no desenvolvimento de espécies cultivadas R. Cient. Faminas, v. 4, n. 1, p.1-8, 2008.

REDDY, K. N.; SINGH, M. Germination and emergence of hairy beggarticks (Bidens pilosa). Weed Sci., v. 40, n. 2, p. 195-199, 1992.

RIOS, A. et al. Efeito da temperatura na germinação de frutos polimórficos de Bidens pilosa L. Malezas, v. 17, n. 2, p. 20-26, 1989.

RIZZARDI, M. H. et al. Perdas de rendimento de grãos de soja causadas por interferência de picão-preto e guanxuma. Ci. Rural, v. 33, n. 4, p. 621-627, 2003.

SAHOO, U. K.; JHA, L. K. Effect of depth and duration of burial on seed viability and dormancy of Bidens pilosa $\mathrm{L}$. and Richardsonia pilosa H. B. K. Seed Res., v. 25, n. 1, p. 5-10, 1998.
SANTOS, J. B. et al. Captação e aproveitamento da radiação solar pelas culturas da soja e do feijão e por plantas daninhas. Bragantia, v. 62, n. 1, p. 147-153, 2003.

SUNDARARAJAN, P. et al. Studies of anticancer and antipyretic activity of Bidens pilosa whole plant. Afr. Health Sci., v. 6, n. 1, p. 27-30, 2006.

TAN, P. V. et al. Effects of methanol, cyclohexane and methylene chloride extracts of Bidens pilosa on various gastric ulcer models in rats. J. Ethnopharmacol., v. 73, n. 3, p. $415-421,2000$.

UBILLAS, R. P. et al. Antihyperglycemic acetylenic glucosides from Bidens pilosa. Planta Med., v.66, n. 1, p. $82-83,2000$.

VALDÉS, H. A. L.; REGO, H. P. L. Bidens pilosa Linné. R. Cubana Plant. Med., v. 6, n. 1, p. 28-33, 2001.

VASQUES, C. A. V. et al. Revisão farmacognóstica do picão (Bidens pilosa L.). Arq. Bras. Med., v. 60, n. 2, p. 107-108, 1986. 